\title{
Freud: Um Monista Mentalista?
}

\author{
Carla Laino Cândido² \\ Universidade de São Paulo
}

\begin{abstract}
RESUMO - É possível conceber a mente como um processo que emerge do corpo sem que possa ser reduzida a ele? Argumentamos que, ao situar as operações cerebrais mais próximas do terreno do significado, Freud desenvolve uma perspectiva energética do psiquismo que, além de se aproximar da moderna teoria científica da complexidade auto-organizada, é capaz de questionar as definições e categorias dualistas que tradicionalmente são aplicadas à relação mente-corpo. Com isso, Freud nos permite pensar em um corpo vivencial e multidimensional que difere do corpo abstrato da Modernidade, paradigmático ainda hoje para a maior parte das ciências que pesquisam o comportamento humano. A partir daí concluímos que, embora haja uma clara hegemonia do conhecimento biológico no estudo da mente, a contribuição freudiana que aponta a impossibilidade de traduzirmos completamente nossa experiência corporal em linguagem não pode ser ignorada, pois permite a conquista de uma nova racionalidade.
\end{abstract}

Palavras-chave: monismo; mentalismo; psicanálise; neurociências.

\section{Freud's Energetic Perspective: A Monism Mentalism?}

\begin{abstract}
Is it possible to conceive the mind as a process that come from the body but not reduced to it? We assume that Freud developed an energetic perspective of psychism approximating cerebral operations from the meaning dimension that besides being near to the modern scientific theory of self-organization discuss the traditional dualistic mind-body definition. Freud's body concept is a vivid and multidimensional category differing from the paradigmatic body concept and this conflict is the point that we want to go deeper here. There is, nowadays, a dominancy of biological knowledge in mind's studies and we concluded that the Freudian contribution that stress the impossibility of transforming body experience to language entirely permit to acquire a new rationality about mind-body relationship.
\end{abstract}

Keys words: monism; dualism; psychoanalysis; neuroscience.

\section{Qual mente?}

O cérebro, como um órgão interior, não conhece o mundo diretamente: os estímulos que chegam aos terminais sensoriais são traduzidos em código e esta tradução é recebida pelo cérebro, que computa as mensagens e as transforma em imagens perceptivas (Morin, 1990). Quer dizer que nosso conhecimento está ligado, originariamente, à nossa relação ativa com o mundo exterior, ou seja, o vínculo fundamental do conhecimento cerebral é o da ação. Nesse sentido, é que Vygotsky (1984) entendia a história do desenvolvimento humano: como a interação entre sistemas psicológicos e modelos de ação cultural-artificial que têm se desenvolvido historicamente. Daí surgiu a noção de que os processos psicológicos humanos são co-construídos, ou seja, a cultura e o comportamento mediado surgiram como um processo único de hominização.

Nesse espírito, propondo que o funcionamento mental e o contexto sociocultural sejam entendidos como momentos dialeticamente interativos, o comportamento humano surge como unidade de análise, organizado por múltiplas influências analiticamente distintas, mas integradas. As próprias estruturas neuropsíquicas se modificam ao longo do tempo,

$1 \quad$ Artigo extraído da tese de doutoramento orientada pelo Prof. Dr. José Roberto Piqueira - Escola Politécnica da USP -São Paulo, com o auxílio da bolsa CAPES

2 Endereço: Rua João de Lacerda Soares, 133/84 - Brooklin, São Paulo, SP, cep: 04707-010. E-mail: carlalcandido@hotmail.com se reaparelham anatomofisiologicamente para atender novas exigências pessoais e ambientais, e novos contextos existenciais (Doin, 2001).

Segundo Bussab e Ribeiro (1998), a percepção integrada, a habilidade de interiorizar representações do mundo, a atividade de produção de bens e o modo de vida social do Homo sapiens fez com que a espécie humana se destacasse quanto à complexidade da cognição. Esse contexto permitiu a linguagem, e, conseqüentemente, a experiência do tempo, a realização de previsões futuras e a construção dos modelos do "eu" e do "não-eu", além da habilidade de comunicar informações pela fala, depois à distância, por meio da escrita, entre os da mesma espécie ou de geração para geração, promovendo acúmulo de conhecimento. Para Rogoff (1994), esses fatores, produzidos através da evolução, funcionam como águas divisórias entre o ser humano e outros animais e tornaram possível o salto qualitativo da cognição humana.

$\mathrm{O}$ fato de ser o homem sensível às contingências ambientais - especialmente históricas e culturais - não implica em negação da história evolucionária; ao contrário, essas contingências e as formas de susceptibilidade humana a elas também podem ser pensadas como produto e instrumento do processo de evolução que produziu a especificidade do Homo sapiens.

$\mathrm{Na}$ escalada evolutiva, do corpo para a mente, do subcortical para o cortical, em que os avanços não excluem os estágios precedentes, porém os integram mais ou menos modificados, vão se juntando características tipicamente humanas. $\mathrm{O}$ processo evolutivo culmina, portanto, com a 
hominização (Doin, 2001), o acesso a um psiquismo aperfeiçoado, ligado às vivências de um eu singular, histórico, sócio-cultural e linguiístico. Esse processo que desemboca naquilo que designamos de mente consciente constitui um aspecto polêmico no estudo científico do comportamento humano. Alguns pesquisadores acham que ela é prerrogativa do humano, outros não.

Acreditamos, como Morin (1990) que, quando acrescentamos o cogito ao computo, ou seja, quando o indivíduo tem consciência de sua própria (in)consciência, e, então, a linguagem é demandada, pode tomar consciência de si através de um instrumento de objetivação. Daí nos diferenciamos da bactéria, pois, como refere Morin (1990), há a construção de um duplo, sendo que o eu é também um outro.

Da mesma maneira, a noção psicanalítica que afirma a existência de um a priori mental, determinador e não determinado pelo meio se opõe veementemente às concepções do funcionamento da mente como um processador de informações super-sofisticado. Repartindo a mente entre a parte que representa o conhecido e a que representa o conhecedor, Freud influenciou a compreensão dos processos humanos. Uma vez que não existe um espectador externo, todo conhecimento implica autoconhecimento ou auto-organização.

\section{A irredutibilidade do mental ao físico}

Freud tinha um modelo teórico sobre a origem do homem: articulou a definição biológica do cérebro como órgão e o conjunto de atividades psíquicas chamada mente e desenvolveu o conceito de aparelho neurocerebral, que é um conceito organizacional. Com Freud, descortinou-se uma realidade que comporta uma face organizacional, uma face do órgão biológico e uma face psíquica, cujo interesse não foi o de reduzi-los um ao outro, mas sim o de pesquisar a natureza de sua articulação.

Se houve resistência em relação a essas concepções psicanalíticas por parte dos neurobiólogos, cientistas cognitivos e dos próprios psicólogos isso ocorreu porque a mente se quer foi reconhecida como objeto de pesquisa em boa parte do século XX; foi honrosamente enterrada e relegada ao descaso durante todo o período em que os conceitos behavioristas dominaram boa parte da compreensão psicológica sobre comportamento humano.

Na década de 1950, com o desenvolvimento tecnológico, surgiu um novo interesse pela mente sob a forma de processamento neural. Com isso, o "mental" pôde ser reconsiderado sob o ponto-de-vista da computação, pois, dessa perspectiva, produzia teorias científicas, cujas hipóteses - as considerações sobre mecanismos cognitivos - eram passíveis de comprovação experimental (Bunge, 1997). Embora alguns pesquisadores cognitivos de orientação mais filosófica tirassem proveito da história do pensamento humano com o objetivo de levantar novas questões metodológicas, epistemológicas e éticas (Serson, 1996), a Psicanálise, que havia dado uma grande contribuição em relação ao mundo privado do homem, foi excluída da construção do projeto científico nascente que pretendia explorar o funcionamento mental. Sem saber como aceitar tal desafio científico, nem as mudanças da sociedade, a Psicanálise desertou do terreno do debate político e intelectual (Roudinesco, 2000).
Nos anos de 1970, em meio a uma onda antibehaviorista que intensificou as teorias chamadas mentalistas, o conceito de consciência ganha aceitação científica, reconhecido como algo que possui uma eficácia causal sobre o comportamento (Sperry, 1996). Essencialmente, para o autor, a nova interpretação de consciência trouxe uma transformação lógica no status científico da experiência subjetiva. Essa vertente de pesquisa que, segundo Sperry, desembocou em uma revolução humanista que se estendeu à Filosofia, Antropologia e à Neurociência, pôde evoluir graças ao desenvolvimento teórico da Neurociência, que contra-atacou as premissas básicas do tradicional paradigma materialista. Sem isso, a mente continuaria não passando de um epifenômeno.

O paradigma materialista vem sofrendo modificações desde 1960, quando uma revolução nas ciências Físicas e Matemáticas impôs uma nova atitude na descrição da natureza. Desenvolvidas paralelamente à teoria termodinâmica dos fenômenos irreversíveis, a teoria dinâmica e a mecânica clássica têm dialogado, no intuito de mostrar que as relações entre o simples e o complexo e entre ordem e desordem são mais estreitas do que imaginávamos. Nesse contexto, alguns sistemas podem gerar, sob certas condições, fenômenos de auto-organização em uma escala macroscópica, em forma de padrões espaciais ou ritmos temporais.

Em relação tanto aos sistemas abertos quanto fechados, quanto mais complicados, com vários elementos interagindo, menor a probabilidade de voltar ao estado inicial, em uma manifestação espontânea de ordem (Lesourne \& Orléan, 1998). Quando os físicos passaram a detectar esse processo em nível físico, químico e biológico, tentando despojar-se de entidades que possam evocar a noção de um controle central surgiram as teorias dos processos que se auto-organizam. Posteriormente, percebendo que a natureza é capaz de se tornar auto-organizada, mas não necessariamente sujeito, redescobriram-na como potencial criador. A criticalidade é a propriedade que os sistemas complexos têm de evoluir para esse ponto espontaneamente, de onde emergem propriedades que não podem ser explicadas pela somatória das ações individuais dos elementos (PerBak, 1997).

Podemos pensar a vivência da consciência humana como a emergência de um fenômeno desse tipo, composto de uma multiplicidade de variáveis em diversos níveis, o que indica que estamos lidando com um problema de extrema complexidade e com vários tipos de causações, tantas são as interfaces entre os níveis externo e interno. O fato de esse sistema evoluir de forma auto-organizada provoca muita controvérsia sobre as propriedade necessárias para que isso aconteça.

Se os componentes dos subsistemas determinam coletivamente a propriedade do todo e essa por sua vez, determina o curso e outras propriedades relacionais dos componentes, então, assumimos no caso do sistema mental, que a existência de um novo tipo de controle pode trabalhar em um caminho de duas mãos: a experiência subjetiva como um derivativo operacional e propriedade emergente da atividade cerebral joga, ao mesmo tempo, um importante papel causal no controle da função cerebral (Sperry,1986).

Apesar dessa perspectiva da complexidade auto-organizada (Camazine \& cols., 2001) lançar uma nova luz a respeito do processo de constituição da mente, que, a meu ver, se aproxima da abordagem freudiana sobre a emergência de uma 
realidade psíquica individual, ainda hoje, no meio científico, sentimo-nos obrigados a converter "um evento mental, que, num dado momento, causa um evento físico", para "um evento físico no cérebro, que tem um aspecto mental, e que causa um outro evento físico" (Elitzur, 1997). Essa última fórmula, consensualmente aceita, indica que somente eventos físicos podem causar outros eventos físicos. Para Morin (1990), esse é o âmago do paradigma de simplificação que guiou a ciência clássica e que ainda perdura, determinando um tipo de pensamento que separa o objeto de seu meio, o físico do biológico, o biológico do humano, reduz o biológico ao físico-químico, o complexo ao simples e unifica o universo. Mas tal história pode estar incompleta.

De acordo com a mecânica clássica, a matéria é dinamicamente completa, isto é, a matéria é controlada por matéria, e o mundo experencial figura como um epifenômeno adicionado ao mundo físico, ou seja, é apenas o resultado de meras excitações ou circuitos neuronais, sem um objetivo ou sentido. Dessa perspectiva não sobra lugar para a intencionalidade, pois, a mente, reduzida a uma testemunha do fluxo dos eventos materiais, transforma-se em um epifenômeno (Stap, 1997). Combatendo tal visão, referem Merzenich e deCharms (1996) que estados comportamentais têm poder de modular a plasticidade cerebral. Além disso, artigos mostram que as propriedades fractais do EEG variam de acordo com o nível da atividade cognitiva (Globus, 1995).

A Psicanálise, uma teoria que assume a irredutibilidade da mente aos fenômenos neurofisiológicos e que considera a importância da experiência do sujeito no fenômeno da plasticidade neural pode ser chamada pela ciência da mente a colaborar com o problema discutido acima. Freud sempre se comprometeu com a idéia de que o componente subjetivo das emoções é visto como parte do modo presente de organização cerebral (Galin, 1996), e que a propriedade global do processo cerebral como uma entidade organizacional coerente determina o tempo e espaço dos padrões de disparo na infraestrutura neuronal.

\section{A realidade psíquica}

A presença das ficções conscientes e dos símbolos oníricos levou Freud a situar as operações cerebrais mais próximas do terreno do significado, e, com isso, a valoração semântica libertou o corpo do domínio da anatomia. Quando, após o Projeto, Freud abriu mão da Biologia como referência, a Psicanálise ganhou contornos próprios e se remete sempre a um sistema psíquico (consciência) que se contrapõe a outro (inconsciente). Nesse ponto situamos, analogamente, a construção de um "duplo", referida por Morin (1990), que diferencia o homem do animal. As verdades racionais, assimiláveis ao processo secundário consciente, deixam de ser as únicas verdades a regerem o ser humano. Há um outro que nos habita, o sujeito do inconsciente; portanto, a verdade do desejo pode ser mais poderosa do que a racional. O cogito não é mais o Todo Soberano (Bastos, 2000).

Esse psiquismo, cujos símbolos encontram relações originais de significado na mente individual, constituídas por regras singulares, porque ancoradas em uma existência corporal única, passou a ser o objeto de estudo da Psicanálise. O mecanismo cerebral está ligado à presença de "energias livres" que não assumem a capacidade de se vincular, e acabam pressionando no sentido de satisfação total, e à presença de "energias quiescentes", que são aquelas em estado de prontidão, à espera de serem investidas em algo (Freud, 1895/1975). O sistema cerebral do Projeto, já se transformando em mental porque altamente catexizado, é capaz de receber um influxo adicional de energia nova e de convertê-la em catexia quiescente, isto é, com capacidade de vincular-se psiquicamente.

Se por acaso uma lembrança, ao ser catexizada, causar desprazer, pode ser que ela conserve qualidades sensoriais capazes de mobilizar afeto em uma pessoa, e não em outra. Esses diferentes efeitos é que parecem depender de regras que emergem da psique individual e que nos remetem à configuração pulsional, ou seja, ao tipo de interação das energias psíquicas que ocorre distintamente em cada ser humano.

Desenvolvendo o modelo energético, Freud começa a explicar a natureza dos processos excitatórios através da intensidade das catexias, que depende das qualidades perceptuais relacionadas à circulação energia interna. Isso implica que o estímulo exterior, ao ser capturado interiormente, é transformado em uma excitabilidade que se associa a um sentido, ou seja, o estímulo externo é transformado em algo distinto dele mesmo. Percebendo que os instrumentos destinados a converter a quantidade externa em qualidade interna se relacionavam às transformações que os estímulos externos sofriam devido aos "invólucros das extremidades nervosas" (o sensível do corpo) funcionarem como uma peneira, reduzindo, limitando ou tornando os estímulos descontínuos, de uma maneira que escapa ao controle do "eu", Freud começa a transformar a exploração neurocientífica da mente em metapsicologia (Brook, 1998).

Freud postulou uma realidade interna que emerge através de um sistema nervoso catexizado, capaz de colorir o real, pois produz desejos cuja satisfação não ocorre por completo, o que implica a forja de metas imaginárias, de modo relativamente independente do comando do "eu" consciente. Segundo Wine (1992), o fator material da realidade, dado por nossa percepção sensorial (corpo vivido), e o formal, representado, com a ajuda de um sistema simbólico, pelos conceitos do entendimento e da memória, são articulados pelo processo secundário, que, através da metaforização, inclui suas diferenças no psiquismo e confere unidade sintética aos fenômenos que experimentamos, gerando semelhança suficiente para permitir uma descarga de energia.

A invenção freudiana da autonomia do corpo em relação a um único sujeito ("eu") e a postulação da emergência de um mundo interior que é diferente do "real", marca um tipo de distinção entre realidade externa e realidade interna bastante original pois situa o sujeito da percepção no limite, na zona fronteiriça entre o exterior e o interior. Porque a pele é um meio-suporte de agenciamento (Gil, 1997) interior-exterior, não se percebe o corpo como se percebe uma coisa. Essa impossibilidade de nos objetivarmos inteiramente, apesar da linguagem, é que vai se constituir como o pontapé inicial do surgimento do psiquismo a partir do corpo e sua capacidade de retroagir sobre o mesmo num processo que qualificamos de auto-organizado.

Concluímos então, que, através da produção de uma realidade interna, o sujeito está livre para imaginar o que quiser, 
mas, ao mesmo tempo, está limitado pelas determinações de uma exterioridade que lhe foge por dois motivos. A realidade material passa a existir conferida a esta uma significação que só pode partir do próprio sujeito; mas, paradoxalmente, o processo de significação reside no poder do simbólico sobre o imaginário (Lacan, 1954/1979). Assim, temos uma exterioridade radical que funda o homem em sua interioridade, ao mesmo tempo em que o exterior só existe se nomeado pelo sujeito. Em consonância com Freud, falamos de uma realidade e de um sujeito que se constituem simultaneamente.

Nesse sentido é que a teoria freudiana instaura um sujeito habitado pela consciência de seu próprio desapossamento (Roudinesco, 2000). Só é livre porque concorda em aceitar o desafio dessa liberdade restritiva e porque reconstrói sua significação.

Nesse novo espaço cognitivo legitimado pelos modelos de pensamento não-lineares que supera os dualismos e nos faz refletir a respeito de um corpo multidimensional diferente do corpo separado da psique da Modernidade (Najmanovich, 1997), qual é a natureza da relação causal envolvida entre mente e corpo? Como Freud se posicionou em relação a essa questão?

\section{Mentalismo não é sinônimo de dualismo}

A idéia de que o processo cerebral físico é causado completamente por ele mesmo sem referência à mente consciente é a premissa básica do behaviorismo e materialismo científico e serve como base para renunciarmos ao fenômeno da experiência subjetiva como um construto explanatório da Ciência. Considerar o processamento cerebral constituído a partir da atividade neuronal e fisioquímica, de onde emergem forças mentais que apresentam eficácia causal sobre o mesmo processamento que as criou é um argumento mentalista que refuta diretamente o materialismo (Sperry, 1986).

A existência e primazia do fenômeno mental e seu papel como determinante causal da função cerebral, que obedece a leis diferentes daquelas de seus componentes materiais, constitui forte indicação de que o funcionamento cerebral transcende os processos eletroquímicos simplesmente. As qualidades subjetivas, cujas propriedades são diferentes daquelas que encontramos nos elementos a partir dos quais elas são feitas, podem ser consideradas reais e causais. Podemos identificar esse processo na aprendizagem, que envolve um novo modo de apreender o si mesmo. Quando nos voltamos para nosso próprio olhar e perguntamos o que vemos, diz Merleau-Ponty (1945/1996), nossa qualidade sensível sofistica-se.

Isso posto, nenhuma descrição do fenômeno físico explica sozinha qualidades subjetivas, porque elas estão em transformação, cada estado sendo criado pelo agora. Segundo Sperry (1996), os diversos jogos possíveis entre a ancoragem no passado - os resíduos de conexões anteriores - e a tensão rumo ao futuro, compõem nosso pano de fundo cognitivo, constituindo uma memória que passa a interpretar as entradas do meio externo.

Alguns sistemas podem ser explicados em termos da interação causal entre seus elementos. A solitude, a liquidez e a transparência são exemplos de características sistêmicas emergentes causais; a mente pode ser vista como uma pro- priedade desse tipo (Searle, 1995). Contudo, um estado mental existe somente como subjetivo, ou seja, como fenômeno em primeira pessoa. Epistemologicamente falando, a visão em primeira pessoa é diferente da visão em terceira pessoa. Por isso, a relação entre corpo e mente, referem Varella, Thompson e Rosh (1993), não é apenas uma especulação teórica, mas também uma prática, uma experiência de vida.

Alguém que tivesse um completo conhecimento da neurofisiologia da dor, ainda assim, não saberia o que é uma dor caso não soubesse como é a sensação da dor. Segundo Searle (1995), esse fato tem conseqüências epistêmicas óbvias: meu conhecimento de que estou com dor tem uma espécie de fundamento diferente daquele do meu conhecimento de que você está com dor. O absurdo máximo é tratar a consciência independentemente da própria consciência, isto é, tratá-la unicamente a partir de um ponto-de-vista de terceira pessoa.

Algumas vezes, a tensão entre a metodologia e o absurdo dos resultados torna-se visível. Na literatura recente, continua Searle, há uma disputa sobre algo chamado qualia e supõe-se que o problema seja: pode o funcionalismo explicar os qualia? O que a controvérsia revela é que o problema da mente consiste, em última análise, por assim dizer, em qualia. $\mathrm{O}$ funcionalismo não pode explicar porque foi concebido em torno de um problema diferente, a saber, atribuições de intencionalidade baseadas em testemunhos de terceira pessoa, ao passo que os fenômenos mentais efetivos não têm nada a ver com atribuições, mas sim com a existência de estados mentais conscientes e inconscientes, ambos fenômenos subjetivos, de primeira pessoa.

O output é transformado em experiência, e, nesse caminho, a própria existência humana se transforma. Penso que esse processo, em função da perspectiva da complexidade, está sendo concebido, cada vez mais, como um objeto de pesquisa considerado por aqueles que estudam o comportamento humano. A teoria de Freud revolucionou nosso entendimento sobre isso porque atribuiu esse processo, em parte, aos eventos neurais não representados na consciência (Roudinesco, 2000).

Desde o Projeto para uma Psicologia Científica, Freud contribui para esclarecer qual é a natureza da relação entre mente e corpo ao assentar a Psicanálise sobre a certeza de que o psiquismo nasce do corpo e o inclui, possuindo, entretanto, características qualitativas que o diferenciam da dimensão somática, fazendo com que seja possível transcendê-la.

Para falarmos em qualia, não basta nos referirmos apenas ao que concerne à representação do organismo consciente; a morte, as paixões, a sexualidade, a loucura, o inconsciente e a relação com o outro moldam a subjetividade de cada um (Roudinesco, 2000). A Psicanálise instaura o primado de um sujeito habitado pela consciência de seu próprio inconsciente, e que, portanto, não pode se restringir ao ser biológico nem a uma máquina desprovida de pensamento e afeto.

Com isso, a Psicanálise vem propor que esse sujeito que não se possui por inteiro, e não mais o organismo, seja considerado o objeto de estudo daqueles que se interessam pela mente.

O foco de pesquisa se desloca da bioquímica e se concentra no problema da construção da intencionalidade. E daí, nossa primeira questão: os afetos não cabem tão somente no 
corpo biológico (Freud, 1926, citado por Bastos, 2000). À medida que se altera o paradigma que orientou a racionalidade moderna, quando o corpo humano era considerado como uma exterioridade a ser controlada, o corpo sensível assume seu papel na produção da subjetividade.

É a partir dessa premissa, que podemos falar sobre a modernidade de Freud ao conceber um corpo vivido que não se reduz ao corpo biológico, idéia precursora da noção de pulsão como algo que surge do somático e funciona como um estímulo para o psíquico. Articulando mente e corpo, Freud rompeu com a Biologia e com as definições tradicionais a respeito do assunto. Era materialista, pois não desprezou o funcionamento cerebral, como demonstra no Projeto, mas, com o psiquismo, soube se descolar do "físico", e abrir portas para sua metapsicologia, inventando o conceito de pulsão. Temos aí o materialista e o mentalista. Assume que mente e cérebro são inseparáveis, e que, ao mesmo tempo, a entidade mental não se reduz ao cérebro. E novamente nos deparamos com um paradoxo: o monismo e o dualismo.

Penso que um dos grandes méritos de Freud tenha sido justamente a capacidade de apontar a inadequação dos termos dualismo-monismo e materialismo-mentalismo quando se pretende descrever a natureza da interação mente-corpo. Concordamos com Sperry (1986): as categorias clássicas não descrevem adequadamente essa relação, pois "mentalismo não é sinônimo de dualismo assim como materialismo não é sinônimo de monismo" (p.79).

Se tivermos, obrigatoriamente que encaixar Freud nessas definições, poderíamos aproximar sua teoria de um monismo mentalista, pois compreendia que os padrões mentais são gerados a partir dos eventos neurais, mas apresentam qualidades próprias, cujos princípios são diferentes dos neurofisiológicos. Além disso, talvez Freud tivesse uma compreensão daquilo que enfatiza Searle (1995): o fato de uma característica ser mental não implica que não seja física; o fato de uma característica ser física não implica que não seja mental; a mente, enquanto subjetiva, enquanto qualitativa, é física, e é física porque mental. Tudo isso mostra a inadequação do vocabulário tradicional. E Freud é moderno porque conseguiu desafiá-lo, e, com isso, criar um conceito ímpar para a compreensão da constituição do psiquismo: a pulsão.

\section{Qual corpo?}

Desde 1895, Freud vinha acentuando o fato de que o aparato psíquico se contrapõe a algo que, embora exterior, faz sua presença no interior do aparato e em função do qual ele se constitui. Segundo Debrun (1996) para que exista autoorganização dentro do organismo, não deve haver entre suas partes nem exterioridade radical, nem fusão, mas uma situação intermediária, ou seja, apesar da hierarquia - em particular a hierarquia mente-corpo - as relações sempre se estabelecem sobre a base "A em relação a B é mais agente do que agido e reciprocamente". Quer dizer: tal relação não é de dominação, mas de influência e supõe uma participação do elemento subordinado. Essa idéia da auto-organização sistêmica está sintonizada com a abordagem freudiana do problema mente-corpo: não há produção do psíquico pelo fisiológico, ou vice-versa, mas, sim, concomitância entre os dois registros.
Freud toma os estímulos corporais como pura dispersão, sem que um tenha a ver com o outro, sem formarem de início, um conjunto estruturado. O corpo do indivíduo, como uma organização única de pulsões, às custas dessa ruptura com a ordem biológica é que permite, a partir de mais complexas relações significantes, a criação de novas e melhores organizações. As funções somáticas básicas, pervertidas pela energia externa que é convertida internamente em excitação, transformam um real que poderia nos subjugar em base da criação de um mundo mental. Esse movimento gera formas individuais de existir no mundo, abre lugar para a diferença individual.

A pulsão, uma construção teórica de Freud, que aponta para a existência de um corpo emocional e de uma mente corporalizada (Najmanovich, 1997) é um conceito altamente polêmico porque critica a noção de corpo e mente com a qual estamos acostumados a trabalhar. Para Freud, cada corpo afeta e é afetado pelo outro, produzindo turbulências e transformações irreversíveis em cada um deles. A alteridade, essa condição de afetar e ser afetado é a referência a partir a qual a subjetividade se faz e se refaz permanentemente. Por corpo desejante, refere Coelho Jr. (1997), entende-se o corpo como pensado pela Psicanálise a partir de uma transformação concebida como necessária: de um corpo biológico em um corpo erógeno; transformação essa marcada pela relação com os outros e pelo desejo dos outros. Por corpo vivido entendese o corpo em relação.

É preciso investigar a noção de corpo na Modernidade porque ela nos atravessa e nos constitui, e também por que, por ter entrado em crise, tanto provoca mal-estar quanto nos impulsiona a buscar novos sentidos. É nessa busca que o conhecimento psicanalítico sobre o binômio mente-corpo e, portanto, sobre o conceito de pulsão, pode ser contextualizado. Para Najmanovich (1997), na contemporaneidade, começamos a poder pensar em um corpo multidimensional: um corpo ao mesmo tempo material e energético, racional e emocional, sensível e mensurável, pessoal e relacional, real e virtual. "O corpo vivencial, diferente do corpo da Modernidade, não é um objeto abstrato (...) não se refere a substância alguma, nem tem um referente fixo fora de nossa experiência como sujeitos encarnados "(p.323).

A partir do momento em que conseguimos ultrapassar a idéia cartesiana de mente e corpo como dois aspectos independentes, a distinção clássica de duas substâncias separadas perde sentido, bem como a própria noção de substância. Notemos: ao transformarmos esse espaço cognitivo, o problema corpo-mente se dissolve.Tanto os dualistas quanto os materialistas estão enganados (Searle ,1995). Ambos aceitam um determinado vocabulário que é obsoleto, pois consiste no ponto de vista de que físico implica não-mental e mental implica não-físico e, com ele, segue um conjunto de falsas hipóteses.

Uma parte dos cientistas encara o materialismo como o único possível enfoque racional da filosofia da mente (Searle, 1995). Outra parte, os mentalistas, propõe que pensemos no seguinte: se há algo que pode ser definido em contraste ao físico é a intangibilidade da experiência consciente (Sperry, 1996). Para muitos leitores, acredito eu, é difícil entender algumas afirmações sobre os estados mentais sem aceitar o aparato cartesiano que tradicionalmente acompanhou o 
reconhecimento dessas afirmações. Searle refere que tanto o dualismo quanto o monismo são falsos porque em geral se supõe que esgotam o campo, não deixando outras opções. Ambos, o dualismo e o materialismo pressupõem a aceitação das categorias cartesianas. Com a noção de pulsão, Freud mostra que esses enfoques, atualmente ainda em voga, são incompatíveis com o que conhecemos a respeito do mundo, tanto a partir de nossas próprias experiências quanto das ciências específicas. Para expressar o que achamos ser verdadeiro, deveremos desafiar as hipóteses por trás do vocabulário tradicional, aconselha Searle (1995). Foi o que Freud fez.

O modelo da auto-organização e o conceito fronteiriço de pulsão, ao colocarem corpo e mente na perspectiva do sujeito encarnado, explorando a multidimensionalidade da experiência, criam uma categoria não clássica de pesquisa que é o devir do sujeito encarnado (Najmanovich (1997), o sensível do corpo (Beividas, 1996), o homem que não se sobrevoa (Debrun,1996), o corpo que seduz e é seduzido (Coelho Jr.,1997), ou, enfim, a auto-criação de um sistema que não pode tomar-se exclusivamente como objeto.

A questão sobre se a mente é ou não causal nos conduz a busca de diferentes paradigmas na ciência, filosofia e cultura em geral. Fica claro, portanto, que o conceito freudiano de pulsão só pode ganhar sentido em um novo espaço cognitivo que ultrapassa as designações habituais - o mentalismo, o materialismo, o monismo e o dualismo. Trazendo a noção de emergência de propriedades a partir da organização interna de um sistema que se estabelece sem um controle central ou externo e que se desenvolve junto com o próprio processo, cujas propriedades emergentes são mais complexas do que os componentes a partir da qual foram criadas, a teoria da auto-organização pode funcionar como uma nova maneira de compreender os fenômenos, inclusive o inconsciente energético, como descrito por Freud. A associação entre Psicanálise e a Auto-organização revela-se produtiva ao questionar as categorias tradicionais que vigoram ainda hoje no estudo da mente.

Porque o homem é constituído de linguagem e com ela produz o mundo, acaba se apegando ao signos como se esses traduzissem uma ordenação imutável que o transcende. Muitos cientistas acreditam que uma concepção da realidade que negue a existência da subjetividade é a única que se possa ter. Ainda existe uma recusa obstinada do real enquanto diferente do verdadeiro.O cientista pretende chegar à Verdade, e, em nome dela, não permite que se tome o desejo por realidade (Olievenstein, 1989). Contudo, esse mundo criado, a partir do qual o homem reconhece o que se passa empiricamente, regula sua experiência e o paralisa.

Traduzimos para a linguagem nossa experiência corporal, mas essa não pode ser totalmente abarcada pela linguagem: pertence a uma outra ordem - é a contribuição de Freud. Embora haja uma clara hegemonia do conhecimento biológico no estudo da mente, essa contribuição não pode continuar sendo simplesmente ignorada. A pulsão, o corpo sexual, o inconsciente, o recurso ao irracional, permitem a conquista de uma outra racionalidade (Roudinesco, 2000), que é diferente daquela baseada exclusivamente no corpo da Anatomia.

Um exemplo da possibilidade de contribuição do monismo mentalista freudiano e de seu derivado - o corpo sexual - ao estudo da mente pode ser identificado no problema da singularidade. Uma vez que a auto-organização é a habilidade de criar complexidade da simplicidade com notável economia, e a pulsão é a desnaturalização do instinto, criando novas necessidades no sistema, não poderíamos pensar a pulsão como uma resposta ao paradoxo biológico de realizar complexidade com uma limitada fonte de informação genética?

Biólogos estão acostumados a considerar as diferenças dos padrões comportamentais como a expressão fenotípica de diferenças genotípicas que evoluíram no tempo em resposta a condições ambientais. Com a pulsão, podemos sugerir que certos padrões específicos podem ser expressões de necessidades originais que foram sendo criadas de maneira autoorganizada em cada sistema mente-corpo. Mas essa história da pulsão potencializar a natureza, e de poder ser estudada interdisciplinarmente como uma complexa estratégia evolutiva é um assunto a ser desenvolvido num próximo artigo.

\section{Referências}

Bastos, L. (2000). O sorriso do lagarto: biotecnologias e afetos. (texto retirado da internet, enviado por cleal@ netflash.com.br).

Beividas, W. (1996). Do sentido ao corpo: semiótica e metapsicologia. Em: Silva, I.A. (org). Corpo e sentido: a escuta do sensivel (pp. 119-134). São Paulo: Editora da Universidade Estadual Paulista.

Brook, A.(1998). Neuroscience versus Psychology in Freud. Em: New York Academy of Sciences (Org.) Neuroscience of the mind on the centennial of Freud's Project for a scientific psychology (pp. 66-77). New York: New York Academy of Sciences.

Bunge,M. (1980). The mind-body problem. Oxford: Pergamon Press.

Bussab, V.S.R. \& Ribeiro, F.L. (1998). Biologicamente cultural. Em: Souza, Freitas \& Rodrigues (Orgs.) Psicologia: reflexões impertinentes (pp. 175-193). São Paulo, Casa do psicólogo.

Camazine, S., Deneubourg, J-L., Franks, N., Theralaz, G., Bonabeau, E. (2001). Self-organization in biological systems. Cambridge, Mass: Princenton University Press.

Coelho Jr., (1997). Corpo construído, corpo desejante, corpo vivo. Em: Lima \& Knobloch. (Orgs.). Cadernos de subjetividade (pp. 401-412). São Paulo: Editora da PUC/ Núcleo de estudos e pesquisas da subjetividade.

Debrun, M. (1996) A idéia de auto organização e a dinâmica da auto-organização primária. Em: Debrun, Gonzales \& Pessoa Jr. (Orgs.), Auto-organização :estudos interdisciplinares em filosofia, ciências naturais e humanas, e artes (pp. 3-59). Campinas: Unicamp/Centro de Logica, Epistemologia e Historia da Ciência.

Doin, C. (2001). A psicanálise e as neurociências: os sonhos. Revista Brasileira de Psicanálise, 35, no. 3, 387-716.

Elitzur, A. (1997). Time and counsciousness: the uneasy bearing of relativity theory on the mind-body problem. Em: Hameroff, Kaszniak \& Scott. (Orgs.). Toward a science of consciousness. The second Tucson discussions and debates (pp. 543-550). Cambridge,MA: MIT.

Freud, S. (1975). Projeto para uma psicologia científica. (A. Melin, trad.).Em: Edição Standart brasileira das obras psicológicas completas de Sigmund Freud (vol.1). Rio de Janeiro: Imago. (Originalmente publicado em 1895).

Galin, D. (1996) The stucture of subjectivite experience: sharpen 
the concepts and terminology. In: Hameroff, Kaszniak \& Scott (Orgs.). Toward a science of consciousness. The first Tucson discussions and debates (pp. 121-140). Cambridge,MA: MIT.

Gil, J. (1997). Metamorfoses do corpo. Lisboa: Ed. Relógio D' água.

Globus, G. (1995). The postmodern brain. BV: John Benjamins

Lacan, J. (1979). O seminário, livro 2: O eu na teoria de Freud e na técnica da psicanálise. (Perrof \& Andrade, trad.). RJ: Jorge Zaar Ed. (Originalmente publicado em 1954)

Lesourne, J. \& Orléan,A. (1998). Advances in Self-organization. London: Ed. Economica.

Merleau-Ponty, M. (1996). Fenomenologia da percepção. (C.A.R. Moura, trad.). São Paulo: Martins Fontes. (Originalmente publicado em 1945)

Merzenich, M. \& deCharms,R. (1996). Neural representation, experience and change. Em: Churchland \& Llinás (Orgs.). The mind-brain continuum (pp. 67-81). Cambridge, Mass: MIT Press.

Morin, E. (1990), O problema epistemológico da complexidade. Lisboa: Biblioteca Universitária, Publicações EuropaAmérica.

Najmanovich, D. (1997). O sujeito encarnado: limites, devir e incompletude. Em: Lima \& Knobloch (Orgs.). Cadernos de subjetividade (pp309-328). São Paulo: Editora da PUC/ Núcleo de estudos e pesquisas da subjetividade.

Olievenstein, C. (1989). O não dito das emoções. (A. Melin, trad.). Rio de Janeiro: Jorge Zaar Ed.
Per Bak (1997). How nature works. Oxford: Oxford University Press.

Rogoff, B. (1994). Observando a atividade sócio-cultural em três planos: apropriação participatória, participação guiada e aprendizado. Em: Wertsch, Del Rio \& Alvarez (Orgs.) Estudos sócio-culturais da mente (pp. 123-142). Porto Alegre: Artes Médicas

Roudinesco, E. (2000). Por que a psicanálise?.(V.Ribeiro, trad.) Rio de Janeiro: Jorge Zahar Ed.

Searle, J. (1995). The rediscovery of the mind. (E. Ferreira, trad.). Cambridge, Mass: MIT Press.

Serson, B. (1996). Ciências cognitivas, semiótica e neurociências. Em: Gonzáles, Lungarzo, Milidoni, Pereira Jr. \& Wrigley (Orgs.). Encontro com as ciências cognitivas (pp. 87-102). Marília: Faculdade de Filosofia e Ciências.

Sperry, R. (1986). Mind-brain interaction: mentalism, yes; dualism, no. Em: Sperry (Org.). Science and moral priority (pp. 77-103). New York: Columbia University Press.

Stapp, HP. (1997). Science of counsciousness and the hard problem. The Journal of mind and behavior, 18, $\mathrm{n}^{\circ} 2$, p. 69-92.

Varella, F., Thompson,E., Rosh, E. (1993). The emodied mind: cognitive science and human experience. Cambridge, Mass: MIT Press.

Vygotsky, L. (1984). A formação social da mente. São Paulo: Martins Fontes

Wine, N. (1992). Pulsão e o inconsciente: a sublimação e o advento do sujeito. Rio de Janeiro: Jorge Zahar Ed.

Recebido em 07.11.2002

Primeira decisão editorial em 11.03.2003

Versão final em 05.06.2003

Aceito em 10.07.2003 